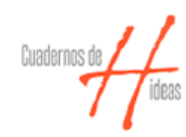

Cuadernos de $\mathrm{H}$ ideas

ISSN: 2313-9048

cuadernosdehideas@perio.unlp.edu.ar

Universidad Nacional de La Plata

Argentina

\title{
El feminismo existencialista de Simone de Beauvoir en La mujer rota
}

Flores Olague, Roberto Gerardo

El feminismo existencialista de Simone de Beauvoir en La mujer rota ${ }^{1}$

Cuadernos de $\mathrm{H}$ ideas, vol. 14, núm. 14, 2020

Universidad Nacional de La Plata, Argentina

DOI: https://doi.org/10.24215/23139048e032 
Artículos

\section{El feminismo existencialista de Simone de Beauvoir en La mujer rota ${ }^{1}$}

Simone de Beauvoir's existentialist feminism in The Broken Woman

Roberto Gerardo Flores Olague

DOI: https://doi.org/10.24215/23139048e032

Universidad Autónoma de Zacatecas, México

robertog.floresolague@gmail.com

Recepción: 01 Febrero 2020

Aprobación: 01 Julio 2020

\section{RESUMEN:}

En el presente artículo se expone el existencialismo feminista de Simone de Beauvoir en una de sus obras literarias más representativas: La mujer rota, la cual fue publicada a finales de la dédcada de los sesenta del siglo pasado. En dicho libro, Beauvoir expresa, a través de tres relatos, su filosofía feminista enmarcada por la influencia de Jean-Paul Sartre, pero a través de su interpretación personal, señalando las condiciones que han llevado a la mujer a vivir sometida en un mundo que espera de ella comportamientos ideales.

Palabras Clave: Simone de Beauvoir, Existencialismo, Feminismo, La mujer rota, Literatura.

\section{Abstract:}

In this article, the feminist existentialism of Simone de Beauvoir is exposed in one of her most representative literary works: The woman destroyed, which was published in the late sixties of the last century. In this book, Beauvoir expresses, through three stories, her feminist philosophy framed by the influence of Jean-Paul Sartre, but through her personal interpretation, pointing out the conditions that have led women to live submissive in a world that expect an ideal behavior from them.

KEYWORDS: Simone de Beauvoir, Existentialism, Feminism, The woman destroyed, Literature.

\section{INTRODUCCIÓN}

Era el año de 1968 y se acababa de publicar, un año antes en Francia, la obra literaria que incumbe a este texto: La mujer rota de Simone de Beauvoir. Las revoluciones políticas, culturales e ideológicas (entre ellas el feminismo, que tenía como elemento esencial criticar la desigualdad social, moral y económica entre hombres y mujeres) se encontraban en efervescencia. ${ }^{2}$ Las ciudades de Praga, México y París eran focos de movimientos sociales que buscaban darle sentido a un orden (en postguerra debido a la Segunda Guerra Mundial y en pleno enfrentamiento de los bloques socialista y capitalista) que no satisfacía a los sectores obreros, estudiantiles, académicos y artísticos; en estas dos últimas esferas, se sitúan dos figuras de renombre en Francia, portavoces del pensamiento filosófico y literario, denominado existencialismo: Jean-Paul Sartre y, la ya mencionada, Simone de Beauvoir. ${ }^{3}$

Ambos establecieron un vínculo intelectual sin el cual no se podrían entender la relación personal que mantuvieron y sus obras más influyentes. De manera general, se puede decir que el pensamiento que ambos defendieron está constituido por los siguientes puntos:

a) Los temas principales se centran en la libertad del ser humano, la angustia de su subjetividad atormentada (influencia del pensamiento de Kierkegaard), la incapacidad de la persona de establecer relaciones personales de sujeto a sujeto, y el gran fracaso del ser humano de realizar su proyecto primordial: ser Dios, único rector de su vida.

b) Los ejes vitales del existencialismo de Sartre, y por ende de Beauvoir, giran en torno a los conceptos de Ser En-si, Ser Para-sí y Ser para-otro; siendo el primero el objeto, carente de movimiento, relaciones y conciencia, teniendo como carácter la instrumentalización. El segundo se refiere al ser humano como 
subjetividad y consciente de su existencia. El tercero implica la renuncia de la libertar personal, dando paso a la cosificación del sujeto: es la llamada mala fe (mauvaise foi). ${ }^{4}$

c) La máxima expresión de la existencia es la libertad (que se refleja como Voluntad Absoluta). El sujeto se hace responsable de sus acciones, dejando atrás la jerarquización de valores establecidos por autoridades morales o civiles, encontrando en el acto libre la autenticidad del ser.

d) La existencia precede a la esencia. Por lo tanto la persona no $e s$, sino que se hace o realiza en su autobiografía. En la existencia se forja la esencia, la cual no es única o universal; cada quien posee una esencia diferente e irrepetible. Hay que evitar a toda costa la cosificación del sujeto, ya que esto resultaría en la "muerte" de la persona.

e) Las relaciones humanas están formadas por el conflicto con el otro.

f) Todo es contingencia y, por lo tanto, no hay razones trascendentales para explicar lo que sucede en el mundo.

Por lo tanto, y de manera muy resumida, se asume que Sartre y Beauvoir analizan la conciencia humana, sobre todo en sus aspectos sentimentales más sombríos y dolorosos: la soledad, la angustia ante la indiferencia del mundo, el desamparo y la tragedia del ser.

Nacida en una familia conservadora cristiana en 1908, Simone de Beauvoir creció bajo la batuta de una moralidad rígida e inflexible. Su madre fue una ferviente católica, dedicada por entero al cuidado de su familia y matrimonio. En su autobiografía, titulada Memorias de una joven formal, Beauvoir comenta sobre ella:

\footnotetext{
Ninguna de mis ti\#as - ni siquiera ti\#a Marguerite que habi\#a sido educada en el Sagrado Corazo\#n- practicaba la religio\#n con tanto fervor: comulgaba a menudo, rezaba asiduamente, lei\# a numerosas obras piadosas. Su conducta se conformaba a sus creencias: pronta a sacrificarse, se dedicaba por entero a los suyos. Yo no la consideraba como a una santa porque la conoci\#a demasiado y porque se enojaba demasiado fa\#cilmente; su ejemplo me pareci\#a aun ma\#s convincente; yo podi\#a, por lo tanto debi\#a, igualarme a ella en piedad y en virtud (Beauvoir, 1967, pp. 21-22).
}

Su padre fue un convencido nacionalista y con principios contradictorios para los hombres y las mujeres. De él se expresa de la siguiente manera:

\footnotetext{
Prohibi\#a que se discutieran los principios del nacionalismo; si alguien mal encaminado pretendi\#a discutirlos se negaba con una gran carcajada: su amor por la Patria se situaba ma\#s alla\# de los argumentos y de las palabras [...] Su moral privada se basaba sobre el culto a la familia; la mujer, como madre, era para e\#l sagrada; exigi\#a de las esposas fidelidad, de las jo\#venes inocencia, pero consenti\#a a los hombres grandes libertades, lo que lo llevaba a considerar con indulgencia las mujeres llamadas livianas (Beauvoir, 1967, p. 20).
}

La educación que recibió se centraba en los esquemas de un aprendizaje para convertirse en la dama perfecta, dispuesta a aceptar su rol como esposa y madre ejemplar. Al ingresar en la Universidad de la Sorbona fue adquiriendo un talante que se fijaba más en las ideas laicas del mundo académico francés: “en un an\#o de Sorbona yo perderi\# a mi fe y mis buenas costumbres" (Beauvoir, 1967, p. 84). La entrada a dicha institución educativa fue para ella un cúmulo de experiencias que le irían abriendo caminos y derroteros para su formación intelectual. Para Beauvoir el estar en la universidad más imporante de Francia fue un reto que no temió aceptar: "En los anfiteatros de la Sorbona codeaba a muchachos y a chicas que habi\#an hecho sus estudios en cursos y colegios desconocidos, en liceos; me evadi\#a del curso De\#sir, afrontaba la verdad del mundo" (Beauvoir, 1967, p. 20).

Lo anterior no estaba libre de situaciones complicadas y desilusionantes para la filósofa francesa. Recuerda que "En la Sorbona mis profesores ignoraban sistema\#ticamente a Engels y a Marx" (Beauvoir, 1967, p. 119). Pero allí conocería a Jean-Paul Sartre, quien ya era reconocido como el pensador más influyente de país 
galo. El pensamiento de Sartre estuvo en un inicio cercano a la fenomenología de Husserl y de Heidegger, aunque con posterioridad se alejó intelectualmente de ésta, lo que le otorgó una reputación relevante. Simone, sin duda, quedó "flechada" por la obra de Sartre, y juntos conformaron la mancuerna, hombre-mujer, más importante del existencialismo francés.

Beauvoir tuvo una mano ágil, un pensamiento hábil y una agudeza necesaria para poder realizar una extensa obra que abarcó gran cantidad de temas. Normalmente se le concedió importancia en el existencialismo francés debido a su relación con Sartre, pero, extrañamente, dentro de esta corriente filosófica, fue uno de los personajes con mayor producción literaria, desde una obra teatro (Las bocas inútiles), diversas novelas (La invitada, La sangre de los otros, Todos los hombres son mortales, Los mandarines, Las bellas imágenes, La mujer rota y Cuando predomina lo espiritual), numerosos ensayos (Para qué la acción, Para una moral de la ambigüedad, El existencialismo y la sabiduría de los pueblos, América al día, El segundo sexo, El pensamiento politico de la derecha, La larga marcha y La vejez) que tocaban temas de filosofía moral, filosofía política y estudios sobre la ancianidad y la muerte. Su libro El segundo sexo, fue el más revelador. Demostró su negativa a la concepción pasiva de la mujer en la historia. Señaló la necesidad de establecer respuestas de "lo femenino" fuera del marco tradicional, desde la autenticidad del ser, sin intervención de "lo masculino", como normalmente había sucedido. Para Beauvoir, no se nacía mujer, se llegaba a serlo con autenticidad y libertad como ejes para conseguirlo.

Tradicionalmente el rol de la mujer en la sociedad había sido construido bajo el papel de la sujeción, de la maternidad responsable, de funcionar como la educadora de buenos hijos y de ciudadanos ejemplares. El ámbito natural de desarrollo de la feminidad estaba en el hogar y lo privado, dejando al hombre el sector de lo público y lo laboral.

El feminismo, del cual es parte Beauvoir, se encontraba en gran expansión en el mundo occidental; la escritora tenía una férrea oposición a la falta de oportunidades de desarrollo de la mujer, oprimida por impostura dogmática patriarcal; la imagen femenina estaba desvirtuada, negándosele toda libertad para elegir por sí misma, lo que le llevó a publicar La mujer rota. ${ }^{5}$

Este libro está construido a partir de tres relatos, tres protagonistas que, a pesar de sus diferentes ambientes económicos y familiares, poseen un rasgo en común: la devastación que sufren ante una existencia que está marcada por el fracaso. Las tres mujeres son portadoras del grito desgarrador que les produce una vida llena de pasajes oscuros, desventuras y mentiras, que les hacen comprender que todo por lo cual han luchado y esforzado ha sido infructuoso, y al revelárseles esto, es tarde, el tiempo se ha ido, la vida se les escapó sin vivirla: no hay libertad, ni autenticidad; existe la mala fe (opresión) y la incapacidad de actuar libremente; es un llamado desde el existencialismo a la necesidad para la realización del ser.

\section{Relato I}

Es cierto que la historia de la humanidad es hermosa -dijo AndréLástima que la de los hombres sea tan triste

(Beauvoir, 2003, p. 63).

La primera historia, La edad de la discreción, posee una redacción sin capitulado y puede considerarse un relato corto. Tiene como personaje principal a "la buena esposa y madre" que se espera de toda mujer. Aquella que se sacrifica en el silencio interior, y que es capaz de cumplir todos los caprichos, deseos, gustos del esposo y del hijo. Una mujer que aun siendo exitosa en el mundo académico, con diversas publicaciones académicas, reconocida intelectualmente, se ha convertido en una persona dependiente de las necesidades de sus dos seres más amados.

La mujer idónea es aquella que sabe callar: "A veces oculto a André caprichos, nostalgias, inquietudes menores" (Beauvoir, 2003, p. 9). El marido y el hijo son los axis mundi de la protagonista. Es a ellos a quienes se les debe todo honor y veneración. La certidumbre de la existencia radica en el compromiso que se tiene en la 
relación, desigual, esposo/esposa o hijo/madre. La estabilidad emocional de la mujer depende, en un sentido meramente posesivo, de las figuras masculinas. Mientras cree tenerlos, no importa lo que pueda suceder en el mundo; pero si hay un distanciamiento emocional, la protagonista empieza a caer en la desesperación, su ser siente una fisura irreparable y rehúsa aceptar tal situación, llegando a exclamar: “...no quiero creer que Philippe haya dejado de pertenecerme" (Beauvoir, 2003, p. 11).

La existencia debe ser aprovechada a toda costa, y una manera de evitarlo es dejando que el tiempo transcurra de forma rutinaria a pesar de los triunfos personales que puedan surgir en la cotidianidad. "Y aquí estoy mirando mi reloj cuyas agujas no dan la sensación de girar" (Beauvoir, 2003, p. 19). Estancamiento del tiempo es igual a la detención de ser en el mundo, de elegir libremente.

Las acciones que se realizan son las que le dan un pleno sentido a la vida misma. Pero incluso las referencias temporales están marcadas por la dependencia respecto al marido y el hijo en esta historia:

¿Qué hacer cuando el mundo se ha descolorido? No queda más que matar el tiempo. Yo también atravesé un mal período, hace diez años. Estaba asqueada de mi cuerpo, Philippe se había vuelto un adulto, después del éxito de mi primer libro sobre Rousseau me sentía vacía. Envejecer me angustiaba. Y después emprendí un estudio sobre Montesquieu, logré que Philippe se diplomara, hacerle comenzar su tesis. Me confiaron cursos en la Soborna que me interesaron aun más que el liceo. Me resigne a mi cuerpo. Me pareció resucitar. Y actualmente, si André no tuviera una conciencia tan aguda de su edad, olvidaría fácilmente la mía (Beauvoir, 2003, p. 15).

Las actitudes destructivas que los seres amados puedan tener, siempre tienen un reflejo inmediato en la mujer que no sabe desarrollar una identidad libre y sin acotamientos sentimentales. "Ya nada lo apasiona. Y es tan derrotista conmigo como él mismo" (Beauvoir, 2003, p. 17). No importa los daños y sufrimientos que los demás generen sobre ella: debe callar y ser paciente, para eso ha sido educada y formada en la sociedad. El estereotipo de la señora abnegada y esclava de su hogar no puede ser superado, dejando coartada la libre elección en sus pensamientos, sentimientos y decisiones.

La crítica a la mujer institucionalizada, sumisa y guardiana de las buenas tradiciones, se hace a través de la burla de aquellas que no seguían esos mismos parámetros de conducta. La protagonista hace burla diciendo:

Conozco a esas jóvenes “a la moda”. Tienen una vaga profesión, pretenden cultivarse, hacer deportes, vestirse bien, mantener impecable su departamento, educar perfectamente a sus hijos, llevar una vida mundana, en una palabra éxito en todos sus planos. Y no tienen interés por nada. Me hielan la sangre (Beauvoir, 2003, p. 20).

No hay nada peor que aquello que aparenta ser algo que no se es. Para Beauvoir, la mujer independiente, que no está bajo la tutela del sistema patriarcal, siempre será considerada una subversiva. La lucha, a la que invita la filósofa francesa, incluso se traslada a un punto donde las propias féminas se convierten en detractoras de su propio género.

Los arrebatos de ira y enojo son propios de las mujeres que asumen la idea de controlar la vida y decisiones de las personas que las rodean, y eso se debe evitar a toda costa. Se han sacrificado tanto que no pueden más que pedir que se les "consulte, por educación, en la toma de resoluciones personales de sus seres queridos. Tuve un arrebato de cólera; era inconcebible que no me hubiera consultado desde que la idea de abandonar la Universidad había brotado en su cabeza” (Beauvoir, 2003, p. 22). La soledad es otro dolor que hiere a la mujer que ha sido apartada de toda voz, incluso en su familia: "Yo fui quien dio forma a su vida. Ahora, asisto a ella desde afuera como un testigo distante" (Beauvoir, 2003, p. 23). Por lo tanto, el resquebrajamiento de los esquemas de comportamiento de los hijos y esposos, crean en la mujer un panorama devastador en su deseo por ser la mujer ideal, que ha cumplido fielmente el rol que le había sido encomendado. Las ideas de los demás son un espejo para sí misma, de su propio existir. Si alguien falla, todos han fracasado; ergo, la reacción es de frustración y coraje cuando la existencia no es como se deseaba o planeaba. En palabras de la protagonista: "Decididamente, ya nada era parecido: ni Milly, ni Philippe, ni André. ¿Y yo?” (Beauvoir, 2003, p. 41). Nada posee entonces certeza, lo que provoca el sentimiento de hundimiento en un hoyo, del cual no hay posibilidad de salir para enfrentar la realidad: “...contemplaba con mirada incrédula el decorado familiar: 
reverso ilusorio y cambiante del vacío adonde me había sumergido" (Beauvoir, 2003, p. 47). Todo es como “...una vasta hipótesis que ya no verifico” (Beauvoir, 2003, p. 48).

El enfrentamiento más claro entre lo que Sartre y Beauvoir denominan autenticidad (Ser para-sí) y la inautenticidad (Serpara-otro), está reflejado en el choque entre la nuera de la protagonista y ésta: "Supongo que su vida siempre ha sido impecable, y que eso la autoriza a juzgar a todo el mundo, desde muy alto" (Beauvoir, 2003, p. 33). El paradigma institucional tiene un talante de juez ante aquello que no es de su misma naturaleza, con aquello que incluso es desafiante, con su otredad, siendo destruida la falsa identidad en la cual se erige: "Estaba aniquilada. Me preguntaba cómo se logra vivir todavía cuando no se espera nada más de sí" (Beauvoir, 2003, p. 52).

Para Beauvoir, la vida es injusta, es atroz y eso hay que aceptarlo libremente. Si la mujer no decide salir de su caparazón, de una feminidad reprimida por una sociedad machista, ve el proyecto de su vida frustrado, tarde que temprano, ante el paso del tiempo y de los cambios en quienes ha puesto toda su confianza. "A mí, la vida iba poco a poco a sacarme todo lo que me había dado..." (Beauvoir, 2003, p. 59).

Esta existencia inauténtica a la cual es necesario darle un sentido de libertad para que tenga un fin digno, está perfectamente reflejada en los diálogos entre André y su esposa: “¿En qué crees? -En el sufrimiento de la gente, y que es abominable. Es necesario hacer todo lo posible para suprimirlo. A decir verdad, ninguna otra cosa me parece importante" (Beauvoir, 2003, p. 63).

\section{ReLATo II}

¡Dios mío! ¡Haz que existas!

(Beauvoir, 2003, p. 95).

El segundo texto, Monólogo, que conforma a La mujer rota, es el más tempestuoso y dramático. Está escrito como un soliloquio breve, en el cual Murielle, la mujer que lo desarrolla, se encuentra atormentada por el ambiente familiar, vecinal y urbano en que se enmarca su vida, lo cual le impulsa a hablar de manera desenfrenada, y que puede notarse en la escritura del relato, donde se carece del signo de puntuación de la coma.

Los dolores que sufre son producto de una infancia, adolescencia y convivencia marital, marcada por el desprecio por su condición femenina. Lo anterior provoca una náusea por la existencia, la cual está resquebrajada por el fracaso de sus relaciones intrapersonales, las cuales se deshacen y dejan una podredumbre e irritación en el interior de la mujer que, de alguna u otra manera, se refleja en sus deseos para con los demás: "iy ellos que creen enloquecerme con sus caras mal lavadas y los aullidos de sus bocinas! Si se hicieran carambola justito aquí bajo mi venta eso sí que me divertiría!" (Beauvoir, 2003, p. 71). "Qué inmundicia su civilización” (Beauvoir, 2003, p. 74).

Cualquier persona que ha renunciado a su libertad, no puede tener más que complejos que se transmitan de forma violenta hacia afuera de sí misma. El actuar de mala fe es correspondiente a una integridad personal desarraigada, sin orden y deseosa de establecerse como mandamás de las preferencias del esposo, de los familiares, de los amigos y los desconocidos. Esto está contrapuesto a la creencia de ser una mujer ideal, con recta moral y sin tacha alguna: "Yo era limpia pura intransigente. Desde la infancia lo tuve metido en la sangre: no hacer trampa” (Beauvoir, 2003, p. 73). Si algo está mal en la sociedad es por culpa de los otros.

Lo más doloroso para esta mujer, es que se ha dado cuenta en la farsa en la que vivía, sobre todo cuando creía que su marido, del cual estaba enamorada, le había engañado con su propia madre, quien a su vez la educó con el estigma de ser moralmente recta, cumpliendo los buenos modales que toda ama de casa debía cumplir. Como amante había fallado. Como esposa no era más que una nada. Como madre no tenía algo que transmitir de valor a su descendencia. Tanto fue su fracaso, que la hija, Sylvie, a la cual le dio gran parte de su vida, se suicidó a corta edad, infringiendo en su madre el agobio y la culpabilidad de no haber hecho algo para evitarlo. Su hijo Francis está más apegado a la figura paterna, la cual le da la estabilidad económica 
que la mujer no puede. Esto no puede más que provocar que el hijo, al ser apartado de su madre, tenga una tendencia hacia un comportamiento ilegal e inmoral: “...un chico privado de su madre siempre termina mal se volverá pillo o un marica...” (Beauvoir, 2003, p. 75). Sólo bajo el manto protector de una madre es como los demás pueden llegar a ser normales. La falta de autenticidad en la mujer, tiende a hacer a los demás objetos de sus cuidados excesivos, que, a la vez, son protecciones a sí misma.

La incapacidad de poder sobresalir en el campo laboral para una mujer y su necesidad de ser mantenida por un varón, el cual, de igual manera, siempre tiene a su favor las leyes, obliga a la protagonista a expresar:

Los hombres se ayudan tanto entre ellos la ley es tan injusta y él tiene tantas influencias que el divorcio sería pronunciado en mi contra. Él se quedaría con Francis más dinero encima y en cuanto al departamento ¡se acabó! Nada que hacer contra ese chantaje asqueante: una pensión y el departamento a cambio de Francis. Estoy en sus manos. Sin plata uno no puede defenderse uno es menos que nada un doble cero (Beauvoir, 2003, p. 75).

Reafirmando la cita anterior, la protagonista está asqueada por la situación favorable de los varones, quienes trabajan y se desarrollan, abriéndoseles fronteras y márgenes más amplios: "Siempre plata si podrán ser bajos los hombres creen que todo puede comprarse para empezar con su dinero...” (Beauvoir, 2003, p. 79). Pero aun llegando a estas conclusiones, no es capaz de aceptar no tener uno a su lado para completar su identidad inacabada.

El sufrimiento más radical proviene del derrumbe de los paradigmas institucionales, morales y familiares en los cuales se han puesto las más profundas ilusiones para realizarse como mujer. Se debe luchar, por difícil que sea la realidad y sus decepciones, para conseguir la estabilidad, la cual sólo puede obtenerse con una familia integra: "iMierda! Quiero que se me respete quiero a mi marido mi hijo mi hogar como todo el mundo." (Beauvoir, 2003, p. 76). "Reventar sola, vivir sola, no, no quiero. Necesito un hombre, quiero que Tristan vuelva, porquería de mundo, gritan, se ríen y aquí estoy yo, muriendo de pie" (Beauvoir, 2003, p. 78) Toda la frustración se concentra en una frase que denota la muerte del ser: "Estoy enterrada." (Beauvoir, 2003, p. 80). El fallecimiento de su hija, la felicidad de su hijo y de su ex marido es algo que no puede soportar, siente que todo lo que poseía le ha sido robado, provocando en ella un desierto, donde no queda más que gritos de dolor exigente, angustia y soledad por ser amada, antes de amarse y ser feliz por sí misma.

\section{ReLato III}

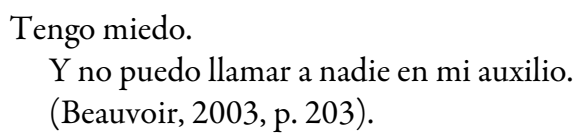

La tercera parte de este libro, La mujer rota, novela corta escrita en forma de diario, tiene como personaje principal a una esposa, Monique, que sufre la desoladora noticia de la infidelidad de su marido, Maurice, quien le ha engañado desde hace ocho años. El sentirse engañada, desilusionada, traicionada por la persona a quien ha consagrado cada día desde que su historia de amor los había unido, es el dolor más hiriente y devastador que ha podido experimentar su matrimonio El gran error de su vida es darle el corazón a cada instante a un hombre que no valora su entrega como esposa y madre, incluso después de renunciar a diversas oportunidades de laborar en trabajos que no fácilmente se le daban a las mujeres. Hay incluso algunos momentos en que todo lo que ha hecho por los demás le ha dejado vacía para sí misma: "Quiero vivir por fin un poco para mí" (Beauvoir, 2003, p. 101). Tiene necesidad de ser auténtica, pero la presión social y familiar no le permite tal cosa. Su ser está abocado totalmente a su esposo e hijas. Sin ellos no es nadie: “...difícilmente soportaría no estar totalmente a disposición de quienes me necesitan” (Beauvoir, 2003, p. 102), lo cual provocará la vaciedad de identidad: "En realidad, estoy desarmada porque nunca imaginé que tenía derechos. Espero mucho de las personas que amo" (Beauvoir, 2003, p. 122); de aquellos que incluso hacen mofa de su "...lado madre-gallina" (Beauvoir, 2003, p. 143). 
La autenticidad del existencialismo es diferente a la que experimenta Monique, la cual está construida desde el sistema patriarcal. Ella añora cuando poseía esta característica que, incluso, Maurice le alababa: "Autentica: era la palabra de moda en esa época. Decía que yo era auténtica” (Beauvoir, 2003, p. 128).

Sus "niñas" son personas adultas. Una de ellas, Lucienne, ha decidido marcharse, con el único fin de sentirse libre, fuera de cualquier cerco familiar que le impida crecer y creer en lo que desea. Es el ejemplo de una mujer que no teme ser cuestionada ni por sus padres; la otra chica, Colette, ha seguido una carrera universitaria plena, pero que ha tomado el camino de la mujer tradicional, siguiendo los pasos de su madre. Es una chica con un esposo fiel, que la hace feliz, y vive tranquilamente en su casa, entregada al hogar; pero tiene una salud débil, muy frágil, tal vez como reflejo de su falta de iniciativa para ser una persona más independiente y firme, sin depender de otros, al igual que su madre. De sus hijas dice lo siguiente: "Pienso que me he ocupado demasiado de las chicas todos estos últimos años: Colette era tan apegada y Lucienne tan difícil. Yo no he estado tan disponible como Maurice podía desearlo" (Beauvoir, 2003, p. 105). Por supuesto: a la falta de atención de Monique, Maurice ha dejado de sentir el acercamiento que toda pareja necesita para seguir amándose. El interés por el otro, alimenta la pasión, acerca a las personas, fortalece los lazos. Pero parece que Beauvoir quiere dejar en claro que como mujer nunca se puede llegar a ser una buena madre y, al mismo tiempo, una esposa ejemplar.

La enemiga, la amante de su marido, Noellie, es una persona que se encuentra en las antípodas de llegar a ser la mujer "ideal" dentro de la sociedad tradicional. Madre irresponsable, esposa infiel, abogada exitosa en el mundo de las leyes, pero fracasada como ama de casa; en palabras de Monique:

Encarna todo lo que nos disgusta: la avidez por llegar, el snobismo, el gusto por el dinero, la pasión de aparentar. No tiene ninguna idea personal, carece radicalmente de sensibilidad: sigue la moda. Hay tanto impudor en sus coqueterías que hasta me pregunto si no es frígida (Beauvoir, 2003, p. 113).

Lo anterior no es algo en malo en realidad; lo que es nauseabundo para la protagonista es para la amante lo que pueda utilizar para acercarse al hombre, ya que tiene mayor libertad de acción, de permisibilidad con ella misma. Por el contrario, la esposa traicionada es incapaz de la improvisación: "Soy tan fiel al pasado que el menor olvido parece un crimen, que uno se siente culpable cuando cambia de gusto o de opinión” (Beauvoir, 2003, p. 167). De tal forma que la tradición, la moralidad se convierte en una náusea constante, un juez que no deja expresar la libertad que toda persona desea, siendo el pilar de la estructura personal. Monique lo afirma diciendo: "No tengo nada más que mi pasado. Pero ya no es ni dicha ni orgullo: un enigma, una angustia" (Beauvoir, 2003, p. 172).

El marido es la droga por la cual ella se siente capaz de realizar cualquier cosa en el mundo; a falta de él su vida es un pozo oscuro y sin fin, que conduce a la más trágica existencia, donde los gritos de tristeza son inaudibles: “iTe necesito y no estás aquí!” (Beauvoir, 2003, p. 104). Agonía en lo más profundo del corazón es lo que siente Monique, ya que ella, la mujer intachable y engañada al mismo tiempo, es la prueba del sacrificio que se hace por amor: "Nunca pedí para mí nada que no quisiera también para él." (Beauvoir, 2003, p. 109); y en Maurice, dice Monique: "No me veía a mí misma más que por sus ojos” (Beauvoir, 2003, p. 146).

En este último relato, Simone de Beauvoir realiza una crítica a la doble moral que le está permita al hombre, quien ha procurado justificar la "debilidad" del sexo masculino por atender a sus necesidades. La mujer, si cae en algún tipo de desliz con otra persona que no sea su pareja, está exponiéndose al rechazo de la sociedad. Para Monique, en su conciencia cree que es normal que Maurice "...haya querido tener una aventura, excusable que al principio me lo haya ocultado; pero de seguro se cansará pronto del asunto" (Beauvoir, 2003, p. 110); llegando al colmo al afirmar "Que un hombre tenga una aventura después de veintidós años de casamiento (...) es normal” (Beauvoir, 2003, p. 105), porque “...la diversidad gusta a los hombres” (Beauvoir, 2003, p. 143).

La virtud a desarrollar ante el desengaño del matrimonio perfecto por parte de la mujer es la paciencia. Aceptar, a las buenas o a las malas, que se ha fracasado, en un primer momento, pero siendo posible la 
reconstrucción de la relación conyugal. Se insiste: la esposa compresiva es, ante todo y sobre todo, paciente. Aunque esto último puede ser sólo un espejismo, un autoengaño que flagela el interior: “...tantas cóleras reprimidas, semejante esfuerzo para guardar las apariencias de serenidad” (Beauvoir, 2003, p. 119).

De lo más doloroso a lo cual debe enfrentarse Monique es darse cuenta que "el tiempo pasa" (Beauvoir, 2003, p. 132). Los años de esfuerzos, los sacrificios dedicados a la labor del hogar, le han marcado físicamente. Ante la sensualidad y erotismo de su contrincante, se encuentra en desventaja. Se ha descuidado, y eso, se quiera o no, marca una diferencia para llamar la atención de Maurice. Noellie al estar en la moda, posee un atractivo extra. Es una mujer que desea explotar su personalidad al máximo, sin reservarse y depender de los cánones morales. Por lo tanto, no es exageración de la protagonista al decir: "Me siento perfectamente miserable" (Beauvoir, 2003, p. 133).

La fatiga y la vaciedad llegan a embargar la identidad y el ser de Monique, su pensamiento ha quedado totalmente oscurecido, condenando a Maurice, pero al mismo tiempo justificándolo. Ella es la verdadera culpable; nadie más tiene la culpa de su muerte en vida: "Si Maurice es un canalla, he desperdiciado mi vida amándolo. Pero a lo mejor tenía razones para no soportarme más. Entonces debo pensarme odiosa, despreciable, sin siquiera saber por qué" (Beauvoir, 2003, p. 153). La libertad ha quedado anulada en su ser, de tal suerte que no sabe ni siquiera cómo mirarse: "Me torturo. ¿Cómo me ven los demás? Y objetivamente, ¿quién soy?” (Beauvoir, 2003, p. 163), “iCómo quisiera verme con otros ojos que los míos!” (Beauvoir, 2003, p. 175). No existe ninguna reivindicación como sujeto por parte de esta mujer. No existe buena fe en ella; al contrario, la mala fe está enraizada en su personalidad, ya que depende siempre de la autorización y buen trato de los otros.

\section{ConCLUSIón}

Se puede decir que Simone de Beauvoir busca, a través de una obra que desestabiliza emocionalmente a sus lectores, develar el rol sumiso y patético que ha encarnado la mujer cultural y económicamente, no por cuestiones fisiológicas, sino desde el parámetro psicosocial.

La mujer ha sido estancada a través de la degradación de como sujeto a objeto por la sociedad patriarcal, que expone a la feminidad carente de conciencia y voluntad. El varón hace de la dama un objeto que no tiene otro fin que cumplir sus roles de madre, esposa e hija ejemplar como se ha visto en las narraciones antes comentadas. La existencia femenina según Beauvoir está completamente desvirtuada, alienada y enmarcada por parámetros intransigentes. La mala fe es el marco común que rige la vida de las protagonistas, y de la cual no pueden sacudirse ante el peso de las instituciones que establecen el debe ser de la mujer en la sociedad.

La mauveis foi conlleva tres síntomas patológicos comunes en las historias contadas en la La mujer rota. En primer lugar el terrible paso del tiempo, reflejado en la "vejez" de las protagonistas, las que sin lugar a dudas experimentan una angustia al sentir que su vitalidad, su cuerpo mismo, ha ido decayendo, de tal suerte que han sentido la impotencia por ser inútil para sus esposos, hijos y familias. El tiempo ha pasado tan vertiginosamente que las energías se han esfumado de sus cuerpos, y ya no queda más que poder brindar a los suyos; su existencia se vuelve injustificable, y de ahí la negación a ese transcurrir del tiempo, lo que produce la inautenticidad del ser en estas mujeres, a actuar de mala fe.

En segundo lugar, la dependencia para con los demás, hace que la soledad que experimentan se convierta en un hecho insoportable; nunca fueron capaces de realizar algo por y para sí mismas; todo estaba ligado a cumplir las expectativas de la familia y la sociedad. Al no poder soportar la soledad, provoca que los sentimientos de odio, angustia, rencor, ira y desaprobación de la vida propia se enraícen más en sus corazones.

Por último, la desilusión al ver terminado el amor conyugal es el mayor mal que puede vivir una mujer, la cual ha sido educada para ser, por encima de todo, la esposa, amante, confidente y amiga de su marido. Si este deber no es cumplido de manera satisfactoria, y el hombre desea terminar la relación, e incluso buscar otra pareja, es culpa de la esposa, de la mujer que no supo cumplir con los cuidados y comportamientos necesarios 
para hacer feliz a su esposo. La culpa moral, según Beauvoir, recae siempre sobre los hombros de la mujer, nunca sobre el hombre, el cual está dispensado, moral, social y, en ocasiones, jurídicamente de sus actos. La mujer es el archivo expiatorio en el cual el varón puede justificar sus acciones de desapego.

Ninguna de las tres mujeres de La mujer rota logra superar su mala fe. Quedan estancadas y sumidas en una terrible desolación. Su incapacidad de ser auténticas les ha acarreado los amargos momentos que nunca esperaron experimentar, porque según ellas habían hecho las cosas como era debido y aceptado.

Simone de Beauvoir realizó la tarea de un médico diagnosticando el estrecho pensamiento machista que subyugaba a la feminidad; pero lamentablemente no dio, en su momento, el antídoto necesario para aliviar esta enfermedad. Años más adelante, con el reforzamiento del movimiento feminista, impulsado en parte por la obra de la escritora francesa, se obtuvieron resultados sociales para la mujer en diversas esferas sociales.

El feminismo que se plantea en este libro es vitalista, nunca violento, bajo la reflexión de la propia vida, que desea regresarle la autenticidad de la existencia a la mujer, abogando por la realización de la individualidad de cada mujer. La toma de decisiones en plena libertad hará más responsable y consciente a la madre, esposa, hija, hermana, novia, soltera, etc., que desee hacerlo, recordando la máxima del existencialismo: $L$ 'homme n'est rien autre que ce qu'il se fait.

\section{REFERENCIAS BIBLIOGRÁFICAS}

Beauvoir, S. (1967). Memorias de una joven formal. (Trad. Bullrich, S.). Buenos Aires, Argentina: Sudamericana. Recuperado de http://www.diariofemenino.com.ar/documentos/Memorias_deunajovenformal.pdf

Beauvoir, S. (2003). La mujer rota (Trad. Sierra, D y Sánchez, N). Buenos Aires, Argentina: Sudamericana. (1967).

\section{Notas}

1 La edición utilizada para este texto es: Simone de Beauvoir, La mujer rota, Sudamericana, Buenos Aires, 2003. Traducción de Dolores Sierra y Néstor Sánchez.

2 En este caso se refiere a las "libertades" morales que, señala el feminismo, el hombre posee por encima de la mujer, como es la posibilidad de que el varón posea varias parejas al mismo tiempo sin ser tildado o acusado socialmente, al menos no como sucede con las mujeres, por dar un ejemplo.

3 El existencialismo en general posee dos escuelas que le representan, aunque puede variar según el autor, y en orden cronológico de aparición son: el existencialismo cristiano, teniendo a Søren Kierkegaard, Fiódor Dostoyevski, Miguel de Unamuno, Gabriel Marcel, Karl Jaspers y Rudolf Bultmann, entre otros, como sus principales representantes; el existencialismo ateo, enraizado principalmente en Francia, donde se encuentran Jean-Paul Sartre, Simone de Beauvoir y Albert Camus.

4 Simone de Beauvoir asume este concepto de Sartre, pero, desde una visión feminista, le denominará opresión en gran parte de su obra escrita.

5 Por mundo occidental se comprenderá a los países que, antes de la caída del comunismo a finales de década de los ochenta, se encontraban en contra del pensamiento socialista y sus directrices política-económica-ideológicas. 